\title{
OBSERVATIONS ON CHYTRIDIACEOUS PARASITES OF PHANEROGAMS. VIII. UROPHLYCTIS (PHYSODERMA) PLURIANNULATUS AND U. MAJUS ${ }^{1,2}$
}

\author{
Frederick K. Sparrow and Yamuna Lingappa
}

\begin{abstract}
A B S T R A C T
Sparrow, Frederick K. and Yamunga Lingappa. (U. Michigan, Ann Arbor.) Observations on chytridiaceous parasites of phanerogams. VIII. Urophlyctis (Physoderma) pluriannulatus and U. majus. Amer. Jour. Bot. 47(3): 202-209. Illus. 1960.-Urophlyctis pluriannulatus, an obligate parasite of Sanicula spp., has an endobiotic phase which is strongly polycentric and produces small crateriform galls on the petioles and blades of the host leaves. The agent accomplishing infection is not known but is probably a zygote. The first cell of the parasite established in the host is the so-called "primary turbinate organ." This becomes multinucleate, is somewhat pyriform and becomes multicellular by 2 methods: (1) by eleavage into peripheral segments; or (2) by division into cells, each with its own cell wall. Replication of the thallus is accomplished by the production of nucleated outgrowths bearing haustoria which elongate, become ribbon-like, somewhat roughened and lumened, and produce distally turbinate organs of a second order. Tertiary, etc. turbinate organs are produced in like manner. Resting spores usually form at the tip of an extremely short outgrowth from the apex of a turbinate organ. These bear a supra-equatorial crown of 7-10 branched haustoria. Rarely, monocentric thalli are formed, in which a single turbinate organ becomes converted into a resting spore. All nuclear division figures were intranuclear. The fungus produced marked enlargement of infected host cells and their nuclei, and caused division of neighboring cells. As development continues, lysis of the surrounding host walls takes place and a large cavity bearing a dense symplast and numerous host nuclei is formed, within which is the thallus of the parasite. At maturity, all traces of symplast and of fungus, except for resting spores, disappear. Urophlyctis majus, a parasite on leaves of Rumex orbiculatus, hitherto known only from its resting spore stage, has a pattern of development strikingly similar to that of $U$. pluriannulatus. Here, however, turbinate cells only form peripheral segments. Furthermore, the "hyphae" are smooth and without a lumen. Aside from size differences, the mature thallus with resting spores, unbranched (not branched) haustorial tufts, etc. is like that of the Sanicula parasite. The galls produced were compartmentalized, dark red to black, usually surrounded by a reddish zone, and early dropped from the leaf. No undoubted evidence of the epibiotic gametangial phase was found in either species.
\end{abstract}

IN THE COURSE of an intensive study of members of the chytrid family Physodermataceae, all of which are obligate parasites of vascular plants, considerable information has been obtained on the two species which appear in the title of this paper. Although our major contribution pertains to Urophlyctis majus, which until now was known only from its resting spores, the other species is discussed first since our material of it was more informative, yielded more stages of development, and served well to interpret development in $U$. majus.

MATERIALS AND METHODS. - Both species of Urophlyctis were collected in the vicinity of Ann Arbor, Michigan, U. pluriannulatus (Berkeley and Curtis) Farlow on Sanicula gregaria, from low ground in a deep woods, and $U$. majus Schroeter on Rumex orbiculatus from the swampy margin of a small lake. The latter chytrid was also recovered from a site in Oakland Co., Michigan, on the same host. Whereas $U$. pluriannulatus can be collected from spring to early autumn, the species on Rumex is

1 Received for publication July 13, 1959.

Acknowledgment is made to the National Science Foundation for financial support of this project.

2 Paper No. 1099, Department of Botany, University of Michigan. more seasonal, appearing in our area in late May and disappearing by early July.

Living material usually was killed and fixed in the field, various well-known agents being employed, the best of which seemed to be Randolph's modification of Navashin's solution (Johansen, 1940). Hand sections of living material were sometimes utilized. Infected host tissue treated for several weeks in $75 \%$ acelic acid or in $10 \%$ sodium hydroxide yielded informative preparations of the parasite when the latter was teased out in a lactophenol-cotton blue solution. Serial sections of material imbedded in paraffin, cut 8-20 $\mu$ thick and stained with such standard combinations as crystal violet and orange $G$, safranin and fast green, or safranin, crystal violet and orange G., and iron-alum hematoxylin with or without orange $G$ as a counter stain, yielded much information on development and host-parasite relationship.

URophlyctis PLURIANNULATUS (Berkeley and Curtis) Farlow.-It will be recalled that probably all members of the Physodermataceae produce 2 contrasting types of thalli in their life cycles. One, the so-called "ephemeral sporangial" stage which is usually invisible to the eye, is epibiotic or somewhat imbedded in hypertrophied host tissue, mono- 
centric with bushy or digitate rhizoids and its sporangium is often (at least in Physoderma) capable of internal proliferation. Discharge of the posteriorly uniflagellate zoospores is by deliquescence of a papilla. The other, endobiotic stage, produces discolored areas, streaks pustules, galls, etc. on the host which are clearly visible macroscopically. This stage is entirely endobiotic, with a richly developed rhizoidal system bearing numerous septate turbinate organs and dark-brown, thick-walled resting spores. There is increasing evidence to support the hypothesis proposed by the senior author (1940) and verified in Physoderma lycopi (Sparrow, 1957b) and Urophlyctis pulposa (Y. Lingappa, 1958), that the epibiotic phase is potentially gametangial and haploid, whereas the endobiotic, resting spore stage, is probably diploid. If so, these fungi would then exhibit heteromorphic alternation of generations.

Evidence for the production of an epibiotic stage by Urophlyctis pluriannulatus is as yet uncertain and precisely what agent accomplishes infection of the host is not known. The first element of the endobiotic phase discernible in our material is a strongly beaked, pyriform or "top-shaped" structure (fig. 1b) $18 \mu$ long $\times 12 \mu$ in greatest diameter which undergoes 1 of 2 methods of development. Either it becomes the primary "turbirate organ" of a strongly polycentric thallus (fig. $4 a, 5 a, 6 b$ ) or, more rarely, it becomes transformed, after a period of enlargment, into a single multinucleate resting spore contained within a lysigenous cavity of the host (fig. 3b). Only the sequence of development of the polycentric thallus was followed here. It is of interest, however, to record for the first time that in this species a monocentric type of endobiotic thallus may occasionally be formed.

Further development of the polycentric thallus is as follows: The aforementioned primary turbinate organ, which is $20-30 \mu$ in greatest width, often appears attached to the inner wall of the host cell (fig. 5a) by a beaked cap of solid wall material. This is undoubtedly a modified portion of the germ tube of the infecting spore which first entered into the host cell. A darkened area of host often seen immediately above this cap no doubt marks the pathway through which the germ tube passed (fig. la, $5 a, 6 a)$. The expanded part of the primary turbinate organ opposite the beak bears a cluster of rather long, finger-like, unbranched, projections which arise from a very short, centrally located stalk. At this time the elements of the cluster are unbranched, rather long and acute rather than spreading in the angle they make with one another (fig. lc).

The youngest primary turbinate organ observed in our sections bore 4 nuclei (fig. 1b). At this stage in the growth of the parasite it was evident that both the host cell and its nucleus had begun to enlarge (fig. Id). When the coenocytic primary turbinate structure attained dimensions of approximately $18 \times 12 \mu$, and bore up to 10 nuclei, cleav. age into cells was initiated (fig. $2 \mathrm{~b}$ ). As a result, a varying number of cells, often 6, was formed, each of which contained 1 or several nuclei. Inasmuch as Jones and Drechsler (1920) previously had indicated that only division of the turbinate cells into peripheral segments occurred in this species as well as in Urophlyctis alfalfae, particular care and attention were given in our material to the nature of this process. Large numbers of sections $6-8 \mu$ thick were studied in order to verify the fact that here in all orders of turbinate organs (i.e., primary, secondary, etc.), cleavage could be into peripheral segments (fig. $4 \mathrm{a}-\mathrm{c}$ ) or by division into cells, each with its own walls, lying within the parent wall of the turbinate organ (fig. $2,4 d, 5$ ).

Following cleavage, one, or usually several of the segments into which the turbinate organ had been divided now produced a bud on its outer surface which gradually enlarged, and into which one nucleus of the segment migrated ( fig. $2 c, d$ ). If more than one nucleus is present in a segment, one migrates and the remainder may enter subsequently formed buds, or may degenerate. By gradual transference of the contents of a segment into the steadily elongating protuberance there is eventually formed a slender, smooth, hypha-like structure $2-3 \mu$ in width with a narrow lumen (fig. $4 \mathrm{~b}, \mathrm{c}, 5 \mathrm{c}, 6 \mathrm{~d}$ ). This terminates distally in a steadily enlarging distention within which is contained the nucleus of the parent segment (fig. 6j,k). Further development involves not only continued elongation of the "hypha" but steady enlargement of the distal swelling. The latter early produces at its apex a delicate tube from which arises a tuft of stubby digitations (fig. $4 \mathrm{~b}$, c). In this manner the rudiment of a turbinate organ of the second order is established. Potentially, every segment of the primary turbinate organ is probably capable of giving rise to slightly smaller secondary turbinate organs in the manner just described although this is seldom achieved. We have found, very rarely, a single turbinate organ with as many as 10 branches emerging from it. By further nuclear and cell divisions in turbinate organs and subsequent production of branches terminating with such structures, there is built up a strongly polycentric thallus bearing turbinate organs of a third (fig. 6) and even fourth order.

One feature of the present fungus deserves special mention, namely, the nature of the mature, so-called "hyphae" or branches arising from the turbinate organs. It will be recalled that these were at first slender, smooth and with a very narrow lumen. As the thallus matures, however, they become up to $6 \mu$ broad, ribbon-like, somewhat roughened, and have a conspicuous lumen ( $\mathrm{fig} .5 \mathrm{c}, \mathrm{d}, \mathrm{e}, \mathrm{f}$ ). Moreover, they envelop in a cup-like fashion the base of the distal turbinate cell (fig. $5 \mathrm{c}, \mathrm{d}, \mathrm{e}$ ). When a branch and its distal turbinate organ of the second degree are displaced as in figure $5 \mathrm{~g}$, the impression is given that the 2 elements are joined by a slender basal peg, possibly a continuation of the lumen. Such broad hypha-like branches were seen by Jones and Drechs. 

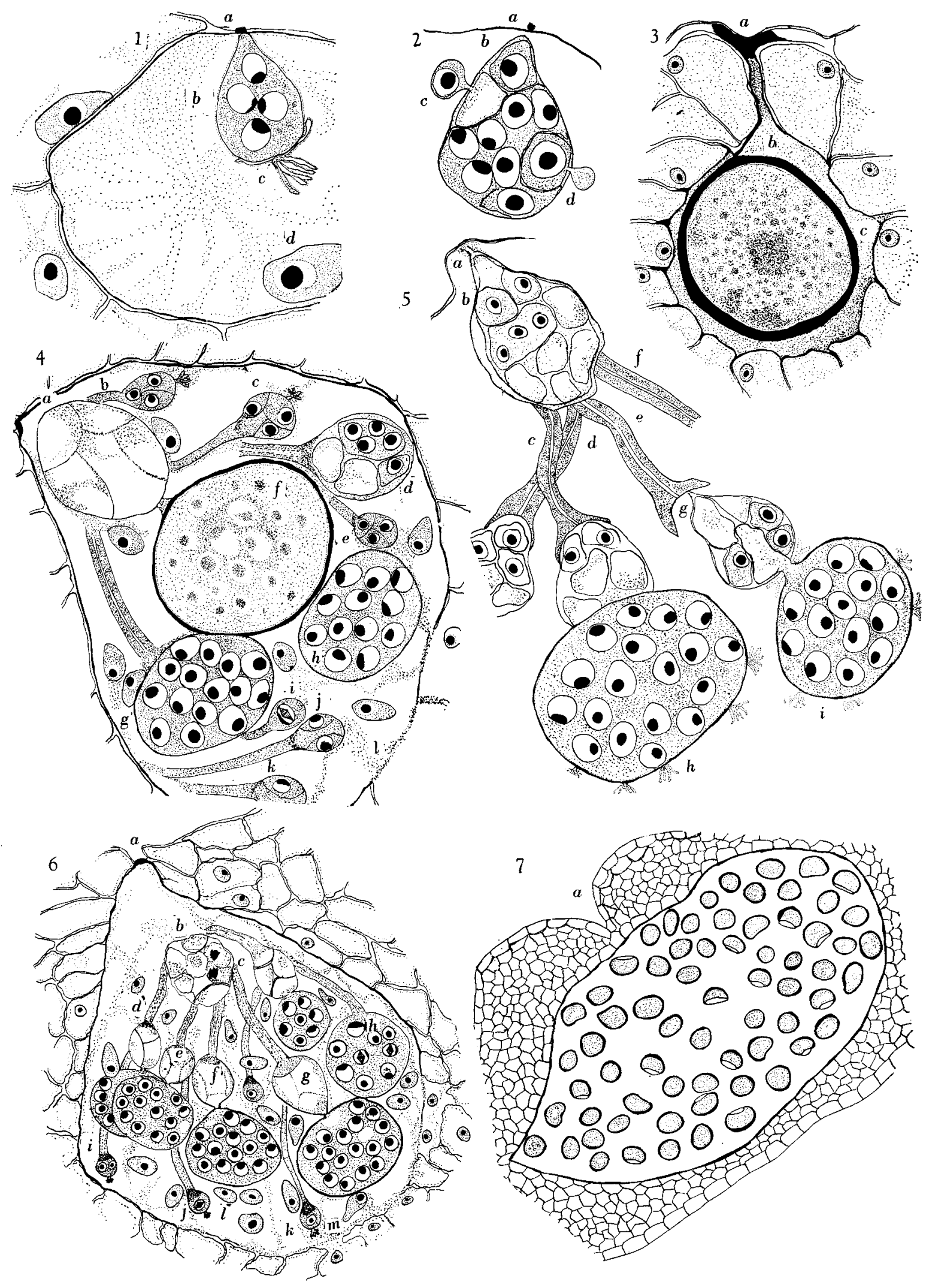
ler (1920), in Urophlyctis alfalfae. They state ". . . the appearance of such swollen mycelium suggests a pathological condition of the parasite rather than a normal one." In our material they were typical of the fully mature, normal thallus and from the figures of $N$. kriegeriana given by Magnus (1897) of that species as well.

Resting spores may originate from the primary turbinate organs (fig. 4f), but most often they are derived from those of the second, third, or higher order (fig. 4g, h; 5h,i; 6c-7g). In any case, only one spore is produced by a single turbinate organ. Its formation is initiated by the emergence of a very short tube from the distal surface of a nucleated segment of the turbinate organ. This tube then produces a radiating tuft of branched, antlerlike haustorical processes after which its apex begins steadily to enlarge into a globose structure, the rudiment of the resting spore. By continued transference of the contents of the central segment of the turbinate organ the rudiment of the resting spore increases in size until it reaches a diameter of approximately $25 \mu$. At this time clusters of branched haustoria can be detected around its supraequatorial region. In stained sections of this and other species, the presence of these haustoria is determined only with great difficulty. Usually careful differential staining is required to demonstrate them. Jones and Drechsler (1920) reported a similar difficulty in Urophlyctis alfallae. They did find them, however, to be easily visible in living material both in the aforementioned species and the present one. We, too, find that in $U$. pluriannulatus they are conspicuous objects on young, living, resting spores which have been teased out of the galls of the host. Furthermore, on such resting spores haustoria are discernible at a much earlier stage in development than on those of comparable age in stained sections.

As the resting spore rudiment increases in size, the number of its nuclei increases. When the spore reaches a diameter of approximately $30 \mu$ its wall, which has been gradually thickening, becomes rigid and amber-colored (fig. $4 \mathrm{~g}, \mathrm{~h}$ ). When fully mature, the spore is slightly elliptical and flattened on the surface to which it is attached to the parent turbinate organ (fig. $4 \mathrm{f}, 6 \mathrm{~g}$ ); the spore is $40.5-56 \mu$ (av. $46.9 \mu$ ) on its broad axis by $43.7-59 \mu$ (av. $50.6 \mu$ ) on its short axis. A supraequatorial ring of branched haustoria remains for a time on the resting spore. In old host galls, however, both the haustoria and the polycentric vegetative system largely disappear, and the resting spores lie loosely in a group within the lysigenous cavity of the host plant (fig. 7). Evidence from our sectioned and living material seems to indicate that, typically, 710 haustorial tufts are found on the maturing spore. When mature spores are treated in caustic soda and mounted in Moyer's medium (containing chloral hydrate) up to 10 pores through which, presumably, haustoria emerged, can be counted. This is in distinction to Jones and Drechsler's observations of presumably the same species on Sanicula menziesii where 14-24 were found. The germination of the resting spores of this species has been reported in another paper by the senior author (Sparrow, 1957a) and is of the non-operculate type.

Cytology.-As previously indicated, the young. est material of the thallus available to us contained four nuclei $4-5 \mu$ in diameter, each with a conspicuous dark-staining nucleolus ( fig. $1 \mathrm{~b}$ ). As the thallus becomes replicated by the extension of the nucleated branch from a segment of the priniary turbinate organ, nuclear divisions take place in the distal

Fig. 1-7. Endobiotic development of Urophlyctis (Physoderma) pluriannulatus on Sanicula gregaria-Fig. 1. Young multinucleate primary turbinate organ, p.t.o. (b) in enlarged host cell. The dark spot at $a$ is the point of infection; at $c$ a tuft of haustoria is seen; $d$, the enlarged host nucleus. $\times 650 .-F i g .2$. P.t.o. which has undergone partial cleavage into individual cells; $a$, the point of infection (spore case-); $b$, a uninucleate segment; $c$, nucleated bud which will ultimately become a turbinate organ, t.o., of second degree borne on a "hypha"; $d$, very young bud into which nucleus of segment has not yet migrated. $\times 800 .-F i g .3$. Resting spore derived from rare instance of monocentric thallus development; $a$, deeply stained depressed infection spot; $b$, resting spore; $c$, lysigenous cavity bearing unassimilated symplast; the host walls lining the cavity have thickened somewhat and thus restrict the fungus. $\times 300$. -Fig. 4. Lysigenous host cavity showing primary, secondary, tertiary, etc. t.o, $a$, empty p.t.o. divided into peripheral segments; $b, c, e, j$, and $k$ are secondary, tertiary, and quaternary young t.o. borne terminally on ribbonlike "hyphae"; $d$, t.o. showing a uni- and a multinucleate cell; $f$, maturing resting spore borne distally on p.t.o.; $\xi$ and $h$, young resting spores; $i$, young t.o., its nucleus in the metaphase stage of intranuclear division; $l$, portion of host walls undergoing lysis; cells lining most of the cavity have slightly thickened walls. $\times 300 .-$ Fig. 5 . Portion of a single thallus; host wall only shown at point of infection $(a) ; a$, remains of infection tube to which is attached the p.t.o.; $b$, uni- and multinucleated segments lying within parent t.o.; $c-f$, broad, fully mature "hyphae showing conspicuous lumens and clasping attachments to secondary t.o.; $g$, displaced t.o. with prolongation suggesting an intimate connection with lumen of "hypha"; $h$, immature multinucleate resting spore bearing antler-like haustoria; $i$, another spore showing basal as well as supraequatorial haustoria. $\ 500$. - Fig. 6 . Lysigenous cavity in gall, the walls of bordering host cells, except in region at $m$, somewhat thickened; point of infection and crateriform opening in gall is at $a ; b$, remains of p.t.o. which has proliferated "hyphae" from segments; $c-g$, secondary t.o. with distal, immature, resting spores; $h$, either immature t.o. or resting spore showing intranuclear division figures; $i-k$, very young tertiary t.o. provided with distal haustoria; $l$, accumulation of host nuclei; $m$, host cells lining cavity undergoing lysis. $\times 300,-F i g .7$. Very large lysigenous cavity in crateriform gall, the spening at $a$; only a few of the many mature resting spores are shown; all traces of the vegetative system have disappeared. $\times 65$. 


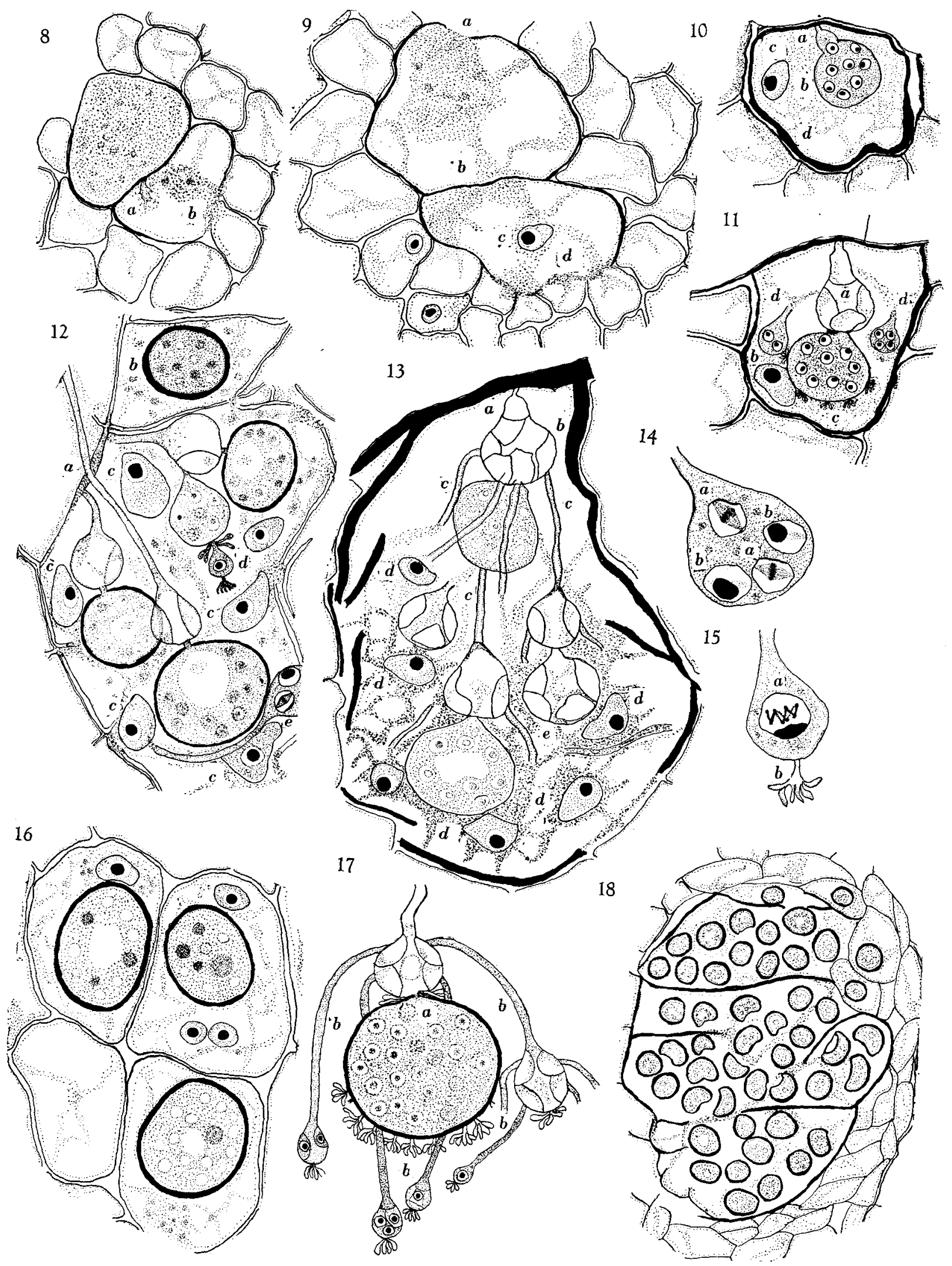


swelling of that branch which is the rudiment of the secondary turbinate structure. Although divisions in developing turbinate organs tend to be synchronous, the nuclei are not all in the same stage of mitosis. Thus, metaphases, late prophases or early anaphases may be found iri a single rudiment (fig. 6h). Divisions are intranuclear (fig. 4i, 6h,j) as reported by Gopalkrishnan (1951) and Yamuna Lingappa (1959a) in other members of the family. At metaphase, the nuclear cavity and the membrane are clearly discernible and usually the laterally displaced nucleolus as well (fig. $4 \mathrm{i}, 6 \mathrm{~h}, \mathrm{j}$ ). The number of chromosomes on the well-defined spindle could not be ascertained with certainty because of their small size. There may possibly be 4 . In all orders of turbinate cells and in the resting spores, nuclei ranged from $3-6 \mu$ in diameter. Mature resting spores always contain many nuclei but these are so obscured by deep-staining spore contents as not to be measurable.

Host-parasite relationship.-Because material on which this study was based had been collected from the field and was not from laboratory-infected host plants killed and fixed after known periods of growth of the parasite, a sequential study of gall formation and lysis could not be obtained and must await further study. Certain aspects of host-parasite relationship are, however, clearly discernible from our material.

As previously indicated, in the earliest stage of thallus development seen by us (fig. lb) the presence of the young primary, 4-nucleate turbinate organ has already resulted in a marked enlargement of the host cell and its nucleus and in the division of neighboring cells. This was also observed in living material. As the fungus spreads, it seemingly lyses (fig. $4 \mathrm{l}, 6 \mathrm{~m}$ ) the surrounding host cell walls and there is produced a large cavity bearing a dense symplast within which the polycentric thallus of the parasite lies along with 6-16 elongated and hypertrophied host nuclei (fig. 41, 6l). It is not actually known at present whether this large number of host nuclei is the result of the dissolution of the walls of numerous host cells and a merging of their contents, or whether the host nucleus has been stimulated to abnormal division, or to a combination of these as found by Y. Lingappa (1959a) in the case of Physoderma (Urophlyctis) pulposum. As the fungus thallus becomes more extensive, the aforementioned dense symplast in the lysigenous cavity is evidently used up by the parasite, for it eventually disappears. The growth and spread of the parasite are usually restricted by a gradual thickening of the host cell walls surrounding the cavity (fig. 3, 4, 6, 7).

The mature host galls in surface view are crateriform, lead-colored pustules on the leaves, petioles and stem. These are either simple, with a single pore leading into the lysigenous cavity, or what is more frequent on leaves, compound. In the latter case, they form an irregular cushion-like protuberance on the under side of the leaf or on the petiole with 2 or more pores leading into separate cavities. Such pores undoubtedly represent points at which the infecting agent gained entrance to the host. In fully matured specimens, the cavities bear a varying number of thick-walled resting spores of the parasite and little else. They are never divided into compartments as in Urophlyctis majus (fig. 18), and $U$. pulposum. Moreover, most traces of the vegeta-

Fig. 8-18. Urophlyctis (Physoderma) majus on leaves of Rumex orbiculatus.-Fig. 8-9. Two structures (each with a basal lysigenous cavity), which are nearly surrounded by proliferated host cells; suspected of being remains of epi. biotic sporangia. In fig. $8 a$, structures suggestive of being basal rhizoids; $8 b$, lysigenous cavity. $\times 280$. -Fig. $9 a$, open tip of gall; $b$, base of possible sporangial structure; $c$, enlarged host nucleus; $d$, host cell walls which have undergone lysis. $\times 300 .-F i g .10$. Young multinucleate p.t.o.; $a$, beak-like portion of germ tube; $b$, body of structure; $c$, enlarged host cell nucleus; $d$, enlarged host cell with markedly thickened walls which contain the parasite. $\times 710$.-Fig. 11. More advanced stage of thallus development; $a$, p.t.o. with attached infection tube and cleaved out peripheral segments, now empty; $b$, enlarged host cell nucleus of infected cell whose walls have notably thickened and will probably restrict spread of fungus; $c$, incipient resting spore with circlet of haustoria; $d$, secondary t.o. X660.-Fig. 12. Portion of infected tissue in which parasite was not contained within a single cavity; $a$, shows a filament passing through hypertrophied host wall without lysing it; $b$, a single resting spore within host cell which has not been lysed or has thickened its walls; $c$, distorted, hypertrophied host nuclei; $d$, rudiment of tertiary t.o. bearing distal and proximal haustoria; the turbinate organ-bearing structure above $d$ appears to have arisen almost directly from peripheral segment of another t.o.; $e$, portion of rudiment of t.o. showing 1 nucleus in metaphase stage of intranuclear division. $\times 660 .-F i g .13$. Large lysigenous cavity in which further fungus invasion of the host has been stopped by enormous thickening of the walls of host cells lining it; $a$, proximal portion of p.t.o. with portion of infection tube; $b$, main body of same, its now empty segments having given rise to at least 5 "hyphae"; $c$, "hypha" bearing secondary turbinate organ, and an immature resting spore; $d$, enlarged host nuclei; $e$, an empty segmented t.o. which appears to have arisen directly from another, a situation probably due to superimposing the two. $\times 690$. -Fig. 14. Young t.o. showing at $a$, intranuclear division at metaphase and $b$, eccentric nucleoli prior to onset of mitosis. $\times 1600 .-F i g .15$. Very young t.o.; $a$, nucleus in what is interpreted as prophase stage, with large peripheral nucleolus; $b$, distal tuft of unbranched hau storia. $\times 1500 .-F i g . ~ 16$. Rare condition in which single resting spores are formed in virtually unaffected host cells. $\times 500 .--F i g .17$. Distal portion of a well-developed thallus teased out of a gall and mounted in lactophenol and cotton blue; $a$, maturing resting spore with basal and supraequatorial tufts of haustoria; $b$, "hyphal" branches terminating in turbinate organs in various stages of development. $\times 650$. - Fig. 18. Compartmentalized gall with mature resting spores; the vegetative system of the fungus has by now disappeared. $\times 150$. 
tive parts of the thallus have disappeared as have the materials of the symplast (fig. 7).

Mature resting spores are ellipsoidal in outline, flattened on one surface, with a thick, brown, smooth outer wall and thin inner one. The majority were $40.6-56 \mu$ (av. $46.8 \mu) \times 43.7-59 \mu($ av. $50.6 \mu)$.

URopHLYCTIS MaJUs Schroeter.-Development. -No epibiotic stage has thus far been seen with any certainty in this species. In an examination of hundreds of sections, 2 lysigenous cavities (fig. $8 \mathrm{~b}$, 9c,d) located in proliferated host cells appeared to bear evidences of having once contained embedded epibiotic structures (fig. 8a, 9a,b) such as have been reported by Schroeter (1882) and Y. Lingap. pa $(1959 \mathrm{~b})$ in the related Urophlyctis pulposa. More and earlier-collected material will have to be examined before confirmation of such a stage occurring in $U$. majus can be made since no rhizoids or zoospores were seen.

Inasmuch as our observations, as in the previously discussed species, are based upon material obtained in the field and not from laboratory-inoculated plants, the nature of the structure producing infection (presumably a zygote) and the very earliest stages in the development of the endobiotic thallus were not obtained. The youngest thallus found is shown in fig. $10 \mathrm{~b}$, in which may be seen a multinucleate primary turbinate organ attached by a neck and narrow tube (fig. 10a) to the wall of the epidermal cell. Hypertrophy of the host cell and thickening of its wall (fig. 10c) in response to the fungus have already been initiated. No well-marked, dark-stained point of infection such as found in the previous species could be discerned. Replication of the thallus from the primary turbinate organ (fig. 11-13, 17) is obviously accomplished only by means of cleavage of peripheral segments, etc., in the same manner as described for Urophlyctis pluriannulatus, and the pattern of thallus development need not be repeated in detail here. It was noted in $U$. majus, however, that the ribbon-like filaments emanating from the turbinate organs were smooth rather than somewhat roughwalled as in the Sanicula parasite and that they lacked the conspicuous lumen (fig. 12a, 13c, 17b) of that fungus. Here, too, haustoria are borne at the tips of the young turbinate cells (fig. 12d, 15b, 17). These are composed of unbranched diverging digitations which arise from a short stalk (fig. 15b). They may often appear sessile or nearly so (fig. 17). Occasionally, as shown in fig. 12d and $13 \mathrm{e}$ a turbinate organ may be directly proliferated by another without any appreciable "hyphal" development.

Resting spores are formed primarily as terminal outgrowths of turbinate organs and, as in Urophlyc. tis pluriannulatus, may be on those of any order (primary, secondary, etc.) (fio. 11c, 13). Circlets of haustoria are produced not only at the point of juncture of resting spore and turbinate organ (fig. 17a) but also on the spore itself in a supraequa- torial ring of $6-20$ or more clusters (fig. 11, 17). In sectioned material the latter tend to disappear as the wall of the maturing resting spore becomes rigid and thickened (fig. 12b, 16) and only a circlet of pits remains to mark their former position.

At maturity, the resting spores are broadly ellipsoidal in outline and flattened on one surface, 34.3 $46.8 \mu$ (av. $40.6 \mu) \times 28-44 \mu$ (av. $35 \mu)$.

Cytology.-The youngest stage in thallus development found in our material is shown in fig. $10 \mathrm{~b}$. Here, the somewhat flask-like primary turbinate organ is already multinucleate. Intranuclear division figures were found in many young, developing turbinate organs. In fig. 14b, a large eccentric nucleolus is seen just prior to the initiation of nuclear division whereas in fig. $15 \mathrm{a}$ what is interpreted as a prophase stage is shown. Here, the nucleolus is flattened against one side of the nuclear membrane. Well-defined intranuclear spindles are present during metaphase stages (fig. 14a). This figure indicates that, as in $U$. pluriannulatus, divisions in a developing turbinate organ tend to bu synchronous but that the nuclei are not all in the same stage of mitosis. Although no division fig. ures were found in developing resting spores mitoses must have occurred since coincident with growth in size there was an increase in the number of nuclei. No chromosome counts of any precision were made; from the division stages shown in fig. 14,15 , four chromosomes are suggested. Nuclei varied from $2.5 \mu$ to $5.5 \mu$ in turbinate organs whereas in the resting spores they were larger.

Host-parasite relationship.-Very early response of the host to the incursion of the parasite seems apparent from such a section as illustrated in fig. 10. Here, the young developing primary turbinate organ has already caused enlargement of the host cell and its nucleus. In this instance the host wall has begun to thicken markedly and undoubtedly would have contained the parasite and restricted its further development. That the host does not always succeed by this method in stopping the interloper may be seen from fig. 13, in which a well-developed thallus of the parasite has grown within a large lysigenous cavity surrounded by much-thickened walls. Thickening of the host walls does not always occur, however, for instances similar to the one shown in fig. 12 and fig. 16 are occasionally found. In the first figure cited, although the walls of invaded cells have broken down and the host nuclei have greatly enlarged (fig. 12c), no wall thickening has taken place. Furthermore, in distinction to other hosts of $U$ ro. phlyctis species, lysis of the walls does not always occur when the outgrowths of turbinate cells pass through them (fig. 12a). It may also be seen from fig. $12 \mathrm{~b}$ and fig. 16, that, rarely, single resting spores are formed in relatively unenlarged and unlysed cells, a condition more typical of a species of Physoderma. Usually, early lysis of the in- 
fected host wall occurs and even before the first resting spore rudiment is laid down on the primary turbinate organ, many neighboring cells have lysed and a large cavity filled with symplast is produced. The fungus undoubtedly makes use of this material in its development, since heavy concentrations of symplast are usually found around young, developing turbinate organs.

The mature gall is divided typically into a varying number of compartments (fig. 18) within which the resting spores lie. By this time, no traces of the vegetative part of the fungus thallus or of the host symplast remain.

Externally, these galls appear on the leaf as dark red to nearly black pustules, usually surrounded by a bright-reddish zone. They may often occur in lines parallel with the midrib of the leaf and close to it. Pustules may be separate or confluent and form erumpent areas up to $1 \mathrm{~mm}$. in width. It was discovered that galls very early fell out of the leaf tissue and the latter became shot through with holes. Such perforations are very common in aging leaves of an individual plant of Rumex orbiculatus. Whether or not they are always caused by the fungus seems unlikely; cutting insects are abundant in some areas supporting growth of the host and may be the real agents involved.

Discussron.-From a study of the endobiotic stages of these fungi 2 features seem worthy of comment. First, it is evident that the polycentric thalli of Urophlyctis pluriannulatus and $U$. majus closely approximate one another in their structure and pattern of development. To be sure, there are structural differences such as size, nature of the ribbon-like rhizoidal system, etc., but these are overshadowed by the striking similarities. In the Rumex parasite, the haustorial appendages on the resting spores are unbranched in contrast to the antler-like ones of $U$. pluriannulatus. Whether or not differences in the number of pits on the resting spores of the 2 species will prove of significance in distinguishing them must await a comprehensive statistical study not only of these species but of what is supposedly the same species on different hosts. The striking difference between the number of pits on spores of $U$. pluriannulatus (14-24) growing on Sanicula menziesii as compared with supposedly the same species growing on Sanicula gregaria, in which only 7-10 were found to be typical, makes such a study imperative.
The second feature of note will only be mentioned briefly here but will be dealt with at length in a forthcoming paper. Our findings as to the nature of the endobiotic thallus of Urophlyctis majus add another species to the group composed of $U$. pulposa, $U$. pluriannulatus, $U$. alfalfae, etc., which form top-shaped turbinate organs, ribbonlike rhizoids, resting spores apically formed on the turbinate organ, and which produce lysigenous cavities within a host gall. Distinct from this group is the galaxy of species with irregular or elongate, transversely or otherwise septate, turbinate organs, delicate rhizoids which "wander from cell to cell" as Magnus (1897) puts it, rather than producing lysis of the host cells, and which form resting spores for the most part laterally at the tip of a tubular prolongation from the turbinate organ. The latter group, considered to be true species of Physoderma, have epibiotic sporangial characters which are also distinctive.

Department of Botany

University OF MichigaN

ANn ARbor, Michigan

\section{LITERATURE CITED}

Gopalkrishnan, K. S. 1951. Development and parasitism of Physoderma graminis (Büs.) Fischer on Agropyron repans (L.) Beauv. Phytopath. 41: 1065-1076.

Johansen, D. A. 1940. Plant microtechnique. McgrawHill Book Co., Inc. New York and London.

Jones, F. R., ANd C. DRechsler. 1920. Crownwart of alfalfa caused by Uropillyctis alfalfae. Jour. Agric. Res. 20: 295-323.

LingaPPA, Y. 1958. Physoderma pulposum. Mycologia $50: 80-84$.

1959a. The development and cytology of the epibiotic phase of Physoderma pulposum. Amer. Jour. Bot. 46: 145-150.

. 1959b. Development and cytology of the endobiotic phase of Physoderma pulposum. Amer. Jour. Bot. 46: 233-240.

Macnus, P. 1897. On some species of the genus Urophlyctis. Ann. Bot. 11: 87-96.

Schroeter, J. 1882. Untersuchungen der Pilzgattung Physoderma. Jahresb. Schles. Ges. Vaterländ. Kultur 60: 198200 .

SPARRow, F. K. 1940. Chytridiaceous fungi in relation to disease in flowering plants, with special reference to Physoderma. In Abstracts of communications, Third Internat. Congress for Microbiology. Dawson, M. Henry (Ed.). New York.

- 1957a. Observations on chytridiaceous parasites of phanerogams. VI. Resting spore germination in Physoderma (Urophlyctis) pluriannulatum. Mycologia 49: $426-429$.

— $1957 \mathrm{~b}$. Observations on chytridiaceous parasites of phanerogams. VII. A Physoderma on Lycopus americanus. Amer. Jour. Bot. 44: 661-665. 